\title{
URINARY LIVER-TYPE FATTY ACID-BINDING PROTEIN AS A MARKER FOR EARLY DIAGNOSIS OF DIABETIC NEPHROPATHY IN TYPE 1 DIABETIC CHILDREN
}

\author{
MONES M ABUSHADY ${ }^{1}$, GIHAN A FATHY ${ }^{1}$, INAS R EL-ALAMEEY ${ }^{1 *}$, ABBAS MA ${ }^{1}$, ESSAM M GALAL ${ }^{1}$, SOHA A NASR \\ ${ }^{1}$ Department of Child Health, Medical Division, National Research Centre, Cairo, Egypt. ${ }^{2}$ Department of Clinical Pathology, Medical \\ Division, National Research Centre, Cairo, Egypt. Email: inasno@hotmail.com
}

Received: 07 November 2017, Revised and Accepted: 12 February 2018

\section{ABSTRACT}

Objectives: Renal failure and premature mortality are fatal prognosis of diabetic nephropathy. To improve patient outcome, early diagnosis of diabetic nephropathy is necessary. The study was designed to evaluate urinary liver-type fatty acid binding protein (L-FABP), as an early biomarker of tubulointerstitial injury, and its association with the clinical characteristics of type 1 diabetic children.

Methods: Fifty randomly selected patients with type 1 diabetes mellitus (DM) attending the diabetes outpatient clinic of Ain Shams University Children's Hospital were included in the study. 50 age and sex-matched healthy subjects were enrolled as controls. Urinary L-FABP, $24 \mathrm{~h}$ urine albumin, hemoglobin A1c (HbA1c), serum creatinine, and lipid profile were measured.

Results: Diabetic subjects had higher mean urinary L-FABP than controls $(\mathrm{p}<0.05)$. In microalbuminuric diabetic subjects, the mean urinary L-FABP was detected to be significantly higher than that in normoalbuminuric diabetic subjects, and significantly higher values of the mean urinary L-FABP were detected in the microalbuminuric and the normoalbuminuric subjects than the controls $(\mathrm{p}<0.05)$. Multiple linear regression analysis showed that duration of DM and HbA1c was the main predictors of urinary L-FABP in diabetic subjects.

Conclusion: In patients with childhood-onset T1D, urinary L-FABP may be used as an indicator of renal injury in early stages of nephropathy, even in the normoalbuminuric state.

Keywords: Urinary L-FABP, Type 1 diabetes, Diabetic nephropathy, Children.

(C) 2018 The Authors. Published by Innovare Academic Sciences Pvt Ltd. This is an open access article under the CC BY license (http://creativecommons. org/licenses/by/4. 0/) DOI: http://dx.doi.org/10.22159/ajpcr.2018.v11i5.23518

\section{INTRODUCTION}

One of the serious and common complications of diabetes is diabetic nephropathy (DN). Renal failure, cardiovascular disease, and premature mortality are some side effects of DN [1,2]. End-stage renal disease (ESRD) is the final outcome of renal failure which requires renal replacement therapy. Diagnosis of DN in its early stage is of crucial benefit to improve clinical consequences [3]. In diabetic patients, albuminuria (albumin excretion rate $>300 \mathrm{mg} /$ day) and deterioration of renal function without urinary tract infection or any other renal disease, determine DN $[4,5]$. Microalbuminuria (MA) (urinary albumin excretion rate [UAE] $30-300 \mathrm{mg} / 24 \mathrm{~h}$ ) is the initial and most frequently used clinical indicator of DN. In $80 \%$ of diabetic patients, the presence of MA was a predictor of future overt DN. After 10 years of follow-up, $30 \%$ of MA diabetic patients proceed to overt nephropathy $[6,7]$. By the time MA becomes clinically evident, advanced glomerular basement membrane alterations may already have existed [8]. In addition, reduction in glomerular filtration rate (GFR) in diabetic patients can occur, leading to renal impairment with normoalbuminuria. Therefore, alternative methods for the early detection of DN are needed $[9,10]$.

Tubular damage markers in the urine can cause and reflect tubular injury in the early course of DN. Urinary excretion of these tubular markers could be used for early detecting progressive DN [11]. In diabetic patients, urinary concentrations of glomerular and tubular markers are high and associated with the severity of DN. Some of these markers are high in diabetic patients with normal kidney function and normoalbuminuria. Therefore, to predict the very early stage of development and progression of DN in diabetics more sensitive and specific markers are needed [12].

Urinary liver-type fatty acid binding protein (L-FABP) is a low molecular weight protein present in the cytoplasm of human proximal tubular cells. It is also expressed at liver level. It is released in urine in response to renal tubular damages. In type 1 diabetic patients presented with normoalbuminuria, increased urinary L-FABP was found, having a predictive role regarding the progression toward MA and MA toward macroalbuminuria [13-15].

Up to the best of our knowledge, no previous studies were done in Egypt assessing the association of urinary L-FABP with T1DM in children. The aim of the current study was to evaluate the association between urinary L-FABP, an early biomarker of tubulointerstitial damage, and the clinical features of normoalbuminuric and microalbuminuric children with T1D) to find out the factors affecting urinary L-FABP

\section{SUBJECTS AND METHODS}

\section{Subjects}

The study population consisted of 50 randomly selected patients with type 1 diabetes mellitus attending the diabetes outpatient clinic of Ain Shams University Children's Hospital. Age ranged from 10 to 17 years with mean age $12.42 \pm 2.31$ years.

Inclusion criteria included diabetes onset before the age of 16 years, insulin dependent from the time of diagnosis, normal serum creatinine $(<0.3 \mathrm{mg} / \mathrm{dl})$, and no signs of clinical nephropathy, inflammatory disease, infectious disease, liver disease, or malignancy.

Fifty age and sex-matched healthy controls were randomly selected from the outpatient clinic of general pediatrics in Ain Shams University Children's Hospital (coming with minor complaints, with no history of either diabetes or kidney disease). 
The study was approved by the Research Ethics Committee of National research center with ethical number 17110 . Written informed consent was obtained from the parents of the participating patients and controls.

\section{Methods}

Glycemic control was assessed by measuring the hemoglobin A1c (HbA1c) by Glycohemoglobin HbA1 test Kit from STANBIO laboratory, San Antonio, Taxes, USA according to the manufacturer instruction. Serum and urinary creatinine were estimated in the studied groups by quantitative calorimetric kit from STANBIO laboratory, San Antonio, Taxes, USA according to the manufacturer instruction. Serum creatinine was used as a marker for GFR. 24 hour urine was collected from the studied groups for measuring urinary creatinine and protein.

Spot urine samples were used to measure urinary L-FABP. Urine samples were collected and centrifuged at $2500 \mathrm{rpm}$ at $4^{\circ} \mathrm{C}$ for $5 \mathrm{~min}$. The supernatants were frozen at $-80^{\circ} \mathrm{C}$ until the biomarker assay was performed. Urinary human L-FABP of the studied population was measured using the 2-step sandwich Enzyme-Linked Immunosorbent Assay (CMIC Co., Ltd., Tokyo, Japan) $[15,16]$. This ELISA kit uses the monoclonal antibodies that specifically recognize human-type L-FABP and its measurable range are between 3 and $400 \mathrm{ng} / \mathrm{ml}$. Measurements were performed in duplicate. MA was defined as UAE between 30 and $300 \mathrm{mg} /$ day or between 30 and $300 \mathrm{mg} / \mathrm{g}$ creatinine on a spot urine sample.

All of the study procedures were conducted in accordance with the medical ethical standards of National Research Center and Ain Shams University, Faculty of Medicine, Cairo, Egypt. Written consents were obtained from the parents of all studied subjects.

\section{Statistical analysis}

SPSS version 22 for Windows (SPSS Inc., Chicago, IL, USA) was used for the statistical analysis. Data were presented by descriptive analysis (case number, mean, standard deviation minimum and maximum) for continuous variables or as raw numbers and percentages for categorical variables. For parametric variables, the difference between two independent samples was measured using unpaired student's t-test. To evaluate the correlation between continuous exposure and continuous covariates, Pearson's correlation analysis was done. Multiple linear regression analysis was done to identify the effect of multiple variables (age, sex, duration of T1DM, fasting blood sugar, HbA1c, and urinary albumin) on a dependent variable (L-FABP). $\mathrm{p}<0.05$ was considered as statistically significant.

\section{RESULTS}

Of the 50 diabetic subjects, $52 \%$ were male and $48 \%$ were female, and the mean age was $12.42 \pm 2.31$ years. In Table 1 , the mean, the standard deviation, minimum, and maximum of the different clinical and laboratory data of the studied subjects (age, body mass index [BMI] z-score, systolic blood pressure [SBP] z-score, diastolic blood pressure [DBP] z-score, HbA1c, 24 h urinary albumin, urinary L-FABP, and lipid profile) are shown.

In diabetic subjects, urinary L-FABP was significantly positive correlated with duration of DM, HbA1c, and $24 \mathrm{~h}$ urinary albumin ( $\mathrm{r}=0.378 \mathrm{p}<0.007, \mathrm{r}=0.419 \mathrm{p}<0.002$, and $\mathrm{r}=0.310 \mathrm{p}<0.028$, respectively) (Table 2).

No significant correlations were detected between urinary L-FABP and each of age, BMI z-score, SBP z-score, DBP z-score, and lipid profile ( $p>0.05)$. On comparing the mean urinary L-FABP between diabetic subjects and controls, a significantly higher mean urinary L-FABP was detected in diabetic subjects than in controls (mean L-FABP was $200.699 \pm 117.203$ vs. $104.815 \pm 22.472$, respectively, $\mathrm{p}<0.05$ ).

In the diabetic microalbuminuric subjects, the mean urinary L-FABP was significantly higher than that in normoalbuminuric subjects (mean

Table 1: Descriptive clinical and laboratory data of the studied subjects

\begin{tabular}{|c|c|c|c|c|}
\hline \multirow[t]{2}{*}{ Variables } & \multicolumn{2}{|c|}{ Mean $\pm S D$ (minimum-maximum) , $(n=50)$} & \multirow[t]{2}{*}{ t-test } & \multirow[t]{2}{*}{$\mathbf{p}$} \\
\hline & Type 1 diabetic subjects & Controls & & \\
\hline Age (years) & $12.42 \pm 2.31(10-17)$ & $12.46 \pm 1.49(10-17)$ & -0.094 & 0.926 \\
\hline BMI z-score & $0.75 \pm 1.71(-2.48-3.81)$ & $0.81 \pm 2.58(-2.56-4.74)$ & 0.1371 & 0.891 \\
\hline SBP z-score & $-0.98 \pm 1.64(-2.01-2.43)$ & $-0.85 \pm 2.21(-3.06-2.87)$ & 0.334 & 0.739 \\
\hline DBP z-score & $0.65 \pm 2.47(-2.13-2.86)$ & $0.61 \pm 2.36(-2.25-2.69)$ & 0.083 & 0.934 \\
\hline $\mathrm{HbA1c} \%$ & $7.76 \pm 1.96(3-14)$ & & & \\
\hline Urinary albumin (mg/day) & $23.11 \pm 27.31(0.6-192.7)$ & & & \\
\hline Urinary L-FABP $(\mathrm{ng} / \mathrm{ml})$ & $200.70 \pm 117.20(55.9-495.5)$ & $104.82 \pm 22.47(40.9-375.5)$ & 5.681 & $0.000^{*}$ \\
\hline Serum cholesterol (mg/dl) & $176.42 \pm 33.31(116-251)$ & $157.74 \pm 25.65(109-223)$ & 3.142 & $0.002 *$ \\
\hline Serum triglyceride $(\mathrm{mg} / \mathrm{dl})$ & $152.98 \pm 28.57(104-211)$ & $132.88 \pm 22.35(80-174)$ & 3.919 & $0.000^{*}$ \\
\hline Serum HDL $(\mathrm{mg} / \mathrm{dl})$ & $61.32 \pm 14.09(34-92)$ & $67.30 \pm 8.72(50-88)$ & -2.552 & $0.012^{*}$ \\
\hline Serum LDL (mg/dl) & $94.26 \pm 32.57(35-155)$ & $69.36 \pm 18.52(36-96)$ & 4.700 & $0.000^{*}$ \\
\hline
\end{tabular}

$P<0.05$ is significant. HbA1c: Hemoglobin A1c, L-FABP: Liver-type fatty acid binding protein, SD: Standard deviation, HDL: High-density lipoprotein, LDL; Low-density

lipoprotein, DBP: Diastolic blood pressure, SBP: Systolic blood pressure, BMI: Body mass index

Table 2: Correlation between L-FABP and another characteristic of diabetic subjects

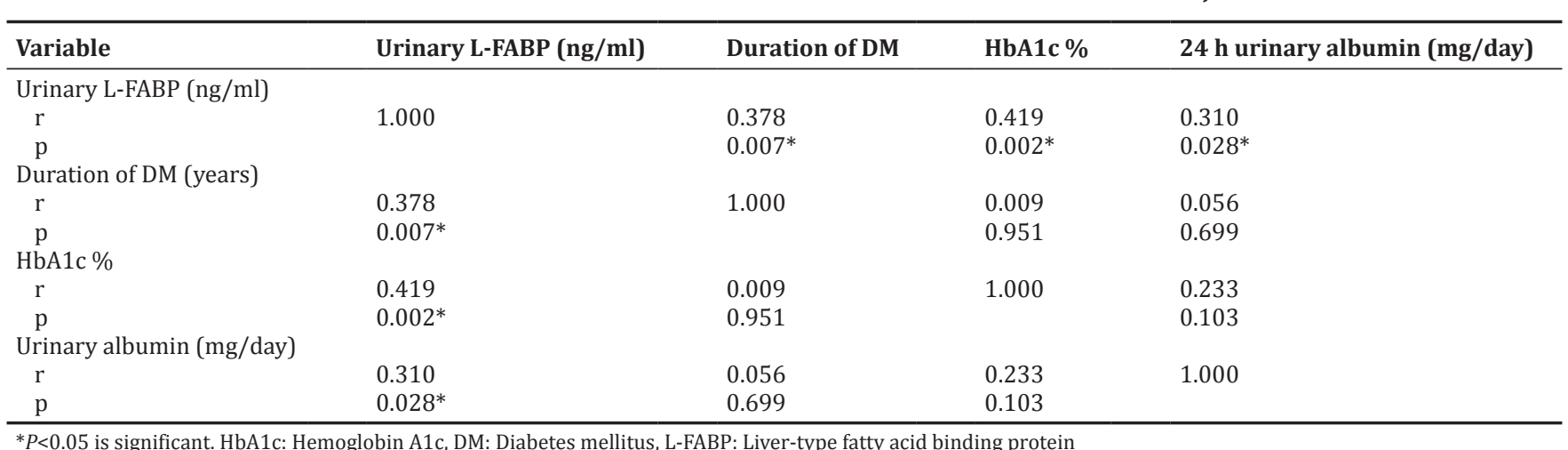


Table 3: Comparison of urinary L-FABP between diabetic subjects and controls and according to albuminuria and HbA1c

\begin{tabular}{|c|c|c|c|c|}
\hline Variable & Group & Mean $\pm S D$ & t-test & $\mathbf{p}$ \\
\hline \multirow{9}{*}{ Urinary L-FABP } & Diabetic patients & $200.699 \pm 117.203$ & \multirow[t]{2}{*}{5.681} & \multirow[t]{2}{*}{$0.000^{*}$} \\
\hline & Controls & $104.815 \pm 22.472$ & & \\
\hline & Normoalbuminuric diabetic patients & $160.115 \pm 92.635$ & \multirow[t]{2}{*}{-5.064} & \multirow[t]{2}{*}{$0.000^{*}$} \\
\hline & Microalbuminuric diabetic patients & $316.208 \pm 103.993$ & & \\
\hline & Normoalbuminuric diabetic patients & $160.115 \pm 92.635$ & \multirow[t]{2}{*}{4.070} & \multirow[t]{2}{*}{$0.000^{*}$} \\
\hline & Controls & $104.815 \pm 22.472$ & & \\
\hline & Microalbuminuric diabetic patients & $316.208 \pm 103.993$ & 3.491 & $0.000^{*}$ \\
\hline & $\mathrm{HbA} 1 \mathrm{c}<8 \%$ & $162.536 \pm 105.649$ & \multirow[t]{2}{*}{-2.524} & \multirow[t]{2}{*}{$0.015^{*}$} \\
\hline & $\mathrm{HbA} 1 \mathrm{c} \geq 8 \%$ & $242.042 \pm 117.057$ & & \\
\hline
\end{tabular}

${ }^{*} \mathrm{p}<0.05$ is significant. HbA1c: Hemoglobin A1c, DM: Diabetes mellitus, L-FABP: Liver-type fatty acid binding protein

Table 4: Multiple linear regression analysis for the predictors of urinary L-FABP

\begin{tabular}{|c|c|c|c|c|c|}
\hline \multirow[t]{2}{*}{ Variables } & \multicolumn{2}{|c|}{ Unstandardized coefficients } & \multirow{2}{*}{$\begin{array}{l}\text { Standardized coefficients } \\
\text { Beta }\end{array}$} & \multirow[t]{2}{*}{$\mathbf{t}$} & \multirow[t]{2}{*}{$\mathbf{p}$} \\
\hline & $\mathbf{B}$ & Standard error & & & \\
\hline Constant & 79.702 & 177.668 & & 0.449 & 0.656 \\
\hline Duration of DM & 12.462 & 4.396 & 0.347 & 2.835 & $0.007^{*}$ \\
\hline Fasting blood sugar & -0.749 & 1.061 & -0.086 & -0.706 & 0.484 \\
\hline $\mathrm{HbA} 1 \mathrm{c} \%$ & 23.007 & 7.524 & 0.384 & 3.058 & $0.004^{*}$ \\
\hline Urinary albumin (mg/day) & 0.888 & 0.533 & 0.207 & 1.666 & 0.103 \\
\hline
\end{tabular}

${ }^{*} \mathrm{p}<0.05$ is significant. HbA1c: Hemoglobin A1c, DM: Diabetes mellitus, L-FABP: Liver-type fatty acid binding protein

L-FABP was316.208 \pm 103.993 vs. $160.115 \pm 92.635$, respectively, $\mathrm{p}<0.05)$. Moreover, the mean urinary L-FABP in both microalbuminuric subjects and normoalbuminuric subjects was compared with the controls, and significantly higher values were detected in the microalbuminuric and the normoalbuminuric subjects than the controls $(316.208 \pm 103.993$ and $160.115 \pm 92.635$, respectively, vs. $104.815 \pm 22.472$, $p<0.05)$. Mean urinary L-FABP was significantly higher in uncontrolled diabetic subjects $(\mathrm{HbA} 1 \mathrm{c} \geq 8 \%)$ than in controlled subjects $(\mathrm{HbA1c}<8 \%)$ (Table 3).

Table 4 shows the predictors of the urinary markers L-FABP through multiple linear regression analysis. Duration of DM and HbA1c was significantly positive associated with the urinary L-FABP in diabetic subjects (B coefficient $=0.347$ and $=0.384$, respectively, $\mathrm{p}<0.05$ ).

\section{DISCUSSION}

In patients with Type 1 diabetes (T1D), high morbidity and premature mortality could be caused by end ESRD [17]. Progressive renal decline develops in about $10 \%$ of patients while UAE is normal, $30 \%$ of those with MA, and $50 \%$ of those with proteinuria. Early and precise diagnosis of DN is of great importance to enhance patient consequences [18-20]. Early DN cannot always be detected by albuminuria which is an indicator of glomerular damage. The early course of DN can be identified by the finding of tubular injury markers in the urine. In normoalbuminuric DN, they may increase even before the diagnosis of MA [5].

Several studies have proved that L-FABP is a promising biomarker of various kidney diseases as type 2 diabetes, vesicoureteral reflux, and B12 deficiency [21-23]. In the current study, urinary L-FABP was significantly higher in T1D subjects than in controls and also in the diabetic group it was significantly higher in microalbuminuric than in normoalbuminuric diabetic subjects. In both normoalbuminuric and microalbuminuric diabetic subjects, urinary L-FABPs were significantly higher than that in controls. That proves the importance of urinary L-FABP as a new marker for earlier identification of nephropathy than MA. Urinary L-FABP was correlated with the duration of DM, HbA1c and $24 \mathrm{~h}$ urinary albumin. Multiple linear regression analysis showed that urinary L-FABP was affected by the duration of diabetes and HbA1c. Hence, urinary L-FABP might reflect the evolution of T1D to DN.
Several studies on adult patients with diabetes have consistently supported that L-FABP is an early marker for tubular injury which is in agreement with the current study. Viswanathan et al. [24] and Panduru et al. [25] found that L-FABP was an independent predictor of progression of DN. Kamijo-Ikemori et al. [26] and Nielsen et al. [13] concluded that high levels of urinary L-FABP could predict DN. In contrast to the present study, Chou et al. [27] postulated that Tubular markers, such as L-FABP, may not be a predictive factor associated with nephropathy in type 2 diabetic patients which differs from the present study in the type of DM (the present study included T1D).

Of the rare studies done on T1D in children, Suh et al. [28] concluded that urinary L-FABP/Cr may be a predictor of kidney damage in early stages of nephropathy in T1D in children, even in the normoalbuminuric state which is in agreement with the current study.

The present study has some limitations to consider. It was a crosssectional study with relative small number of subjects. Further studies including large numbers of subjects and longitudinal observations are needed to prove the association of urinary L-FABP with DN in pediatric patients with T1D. The cutoff value of urinary L-FABP for predicting DN in children has not been determined and in the current study, diabetic subjects had preserved renal function. Further studies are required to define the cutoff value of urinary L-FABP for early detection of DN in T1DM.

In conclusion, urinary L-FABP may be an early marker of diabetic nephropathy in children with T1D, regardless of the state of albuminuria. High urinary L-FABP is associated with uncontrolled and long duration of T1D independent of albuminuria.

\section{REFERENCES}

1. Groop PH, Thomas MC, Moran JL, Wadèn J, Thorn LM, Mäkinen VP, et al. The presence and severity of chronic kidney disease predicts allcause mortality in Type 1 diabetes. Diabetes 2009;58:1651-8.

2. Gluhovschi C, Gluhovschi G, Petrica L, Timar R, Velciov S, Ionita I, et al. Urinary biomarkers in the assessment of early diabetic nephropathy. J Diabetes Res 2016;2016:4626125.

3. Jahidu IM, Sridevi C, Azli SO, Muhammad ZI. Diabetic nephropathy an obvious complication in long term Type 1 diabetes mellitus: A case study. Ascian J Pharm Clin Res 2017;10:4-7. 
4. Atkins RC, Zimmet P. Editorial: Diabetic kidney disease: Act now or pay later. Kidney Int 2010;77:375-7.

5. Fiseha T, Tamir Z. Urinary markers of tubular injury in early diabetic nephropathy. Int J Nephrol 2016;2016:4647685.

6. Rossing P, Hougaard P, Parving HH. Progression of microalbuminuria in Type 1 diabetes: Ten-year prospective observational study. Kidney Int 2005;68:1446-50.

7. Currie G, McKay G, Delles C. Biomarkers in diabetic nephropathy: Present and future. World J Diabetes 2014;5:763-76.

8. Perkins BA, Ficociello LH, Roshan B, Warram JH, Krolewski AS. In patients with Type 1 diabetes and new-onset microalbuminuria the development of advanced chronic kidney disease may not require progression to proteinuria. Kidney Int 2010;77:57-64.

9. Perkins BA, Ficociello LH, Silva KH, Finkelstein DM, Warram JH, Krolewski AS, et al. Regression of microalbuminuria in Type 1 diabetes. N Engl J Med 2003;348:2285-93.

10. Caramori ML, Fioretto P, Mauer M. Low glomerular filtration rate in normoalbuminuric Type 1 diabetic patients: An indicator of more advanced glomerular lesions. Diabetes 2003;52:1036-40.

11. Bonventre JV. Can we target tubular damage to prevent renal function decline in diabetes? Semin Nephrol 2012;32:452-62.

12. Nauta FL, Boertien WE, Bakker SJ, van Goor H, van Oeveren W, de Jong PE, et al. Glomerular and tubular damage markers are elevated in patients with diabetes. Diabetes Care 2011;34:975-81.

13. Nielsen SE, Sugaya T, Hovind P, Baba T, Parving HH, Rossing P, et al. Urinary liver-type fatty acid-binding protein predicts progression to nephropathy in Type 1 diabetic patients. Diabetes Care 2010;33:1320-4.

14. Lee $\mathrm{CH}$, Lam KS. Biomarkers of progression in diabetic nephropathy: The past, present and future. J Diabetes Investig 2015;6:247-9.

15. Kamijo A, Sugaya T, Hikawa A, Okada M, Okumura F, Yamanouchi M, et al. Urinary excretion of fatty acid-binding protein reflects stress overload on the proximal tubules. Am J Pathol 2004;165:1243-55.

16. Kamijo A, Kimura K, Sugaya T, Yamanouchi M, Hikawa A, Hirano N, et al. Urinary fatty acid-binding protein as a new clinical marker of the progression of chronic renal disease. J Lab Clin Med 2004;143:23-30.

17. Jerine PS, Evan PS. Global current trends in natural products for diabetes management. Int J Pharm Pharm Sci 2016;8:20-8.
18. Krolewski AS. Progressive renal decline: The new paradigm of diabetic nephropathy in Type 1 diabetes. Diabetes Care 2015;38:954-62.

19. Krolewski AS, Niewczas MA, Skupien J, Gohda T, Smiles A, Eckfeldt $\mathrm{JH}$, et al. Early progressive renal decline precedes the onset of microalbuminuria and its progression to macroalbuminuria. Diabetes Care 2014;37:226-34.

20. Skupien J, Warram JH, Smiles AM, Niewczas MA, Gohda T, Pezzolesi MG, et al. The early decline in renal function in patients with Type 1 diabetes and proteinuria predicts the risk of end-stage renal disease. Kidney Int 2012;82:589-97.

21. Ito H, Yamashita H, Nakashima M, Takaki A, Yukawa C, Matsumoto S, et al. Current metabolic status affects urinary liver-type fatty-acid binding protein in normoalbuminuric patients with Type 2 diabetes. J Clin Med Res 2017;9:366-73.

22. Benzer M, Tekin Neijmann S, Gültekin ND, Uluturk Tekin A. Urinary L-FABP as a marker of vesicoureteral reflux in children: Could it also have a protective effect on the kidney? Int Urol Nephrol 2017;49:1-2.

23. Güneş A, Aktar F, Tan İ, Söker M, Uluca Ü, Balık H, et al. Urinary levels of early kidney injury molecules in children with vitamin B12 deficiency. Arch Argent Pediatr 2016;114:453-7.

24. Viswanathan V, Sivakumar S, Sekar V, Umapathy D, Kumpatla S. Clinical significance of urinary liver-type fatty acid binding protein at various stages of nephropathy. Indian J Nephrol 2015;25:269-73.

25. Panduru NM, Forsblom C, Saraheimo M, Thorn L, Bierhaus A, Humpert PM, et al. Urinary liver-type fatty acid-binding protein and progression of diabetic nephropathy in Type 1 diabetes. Diabetes Care 2013;36:2077-83

26. Kamijo-Ikemori A, Sugaya T, Ichikawa D, Hoshino S, Matsui K, Yokoyama T, et al. Urinary liver type fatty acid binding protein in diabetic nephropathy. Clin Chim Acta 2013;424:104-8.

27. Chou KM, Lee CC, Chen CH, Sun CY. Clinical value of NGAL, L-FABP and albuminuria in predicting GFR decline in Type 2 diabetes mellitus patients. PLoS One 2013;8:e54863.

28. Suh JS, Kim SH, Cho KS, Jung IA, Cho WK, Jeon YJ, et al. Urinary markers in the early stage of nephropathy in patients with childhoodonset Type 1 diabetes. Pediatr Nephrol 2016;31:623-31. 